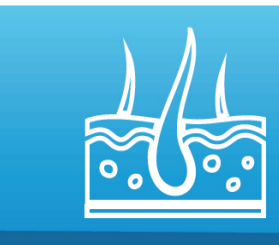

DERMATOLOGY

\title{
Nevus sebaceus of Jadassohn - high frequency ultrasound imaging and videodermoscopy examination. Case presentation
}

\author{
Artur Bezugly ${ }^{1}$, Tatiana Sedova², Pavel Belkov ${ }^{3}$, Damir Enikeev ${ }^{4}$, \\ Ruslan Voloshin ${ }^{5}$
}

1) Dermatology Department, Academy of Postgraduate Education under the Federal State Budgetary Unit "Federal Scientific and Clinical Center for Specialized Medical Assistance and Medical Technologies of the Federal Medical Biological Agency, Russia

2) Dermatology Department, E.A. Vagner Perm State Medical University, Russia

3) ANTA - Med clinic, Moscow, Russia

4) Pathophysiology Department, Bashkir State Medical University of the Ministry of Healthcare of the Russian Federation

5) Dermatology Department, Rostov State Medical University, Russia

DOI: $10.15386 / \mathrm{mpr}-1658$

Manuscript received: 17.04 .2020

Received in revised form: 16.06 .2020

Accepted: 01.07.2020

Address for correspondence:

drarturbezugly@gmail.com

This work is licensed under a Creative Commons Attribution-NonCommercialNoDerivatives 4.0 International License

\begin{abstract}
Nevus sebaceus of Jadassohn (NSJ) is a congenital cutaneous hamartoma mainly developing from pilosebaceous unit cells. NSJ has the potential to develop into a variety of benign and malignant tumors, which are not limited to sebaceous differentiation. The dynamical monitoring for the earliest malignant transformation is necessary. Herein, we report the combined noninvasive NSJ examination with videodermoscopy in polarized and non-polarized light and high-frequency ultrasound (HFUS) imaging at 33 and $50 \mathrm{MHz}$. Typical NSJ dermoscopic signs where described, the internal nevus structure and its location, depths, and margins with surrounded tissues were examined with high-frequency ultrasound.

Some HFUS characteristics for NSJ were described. Videodermoscopy and highfrequency ultrasound combined examination could be useful for NSJ dynamical monitoring in order to detect malignant transformation and to define necessary and sufficient tissue excision volume in case of surgical treatment.
\end{abstract}

Keywords: nevus sebaceus of Jadassohn, high-frequency ultrasound skin imaging, videodermoscopy

\section{Introduction}

Tumors and tumor-like skin appendages formations are a heterogeneous neoplasms group, which is variable in origin, and mainly developing from pilosebaceous unit cells [1]. The nevus sebaceus of Jadassohn (NSJ), described by Joseph Jadassohn in 1895 [1-6], is one of the most common.

NSJ is a congenital hamartoma, consisting of sebaceous, epithelial, and apocrine structures, and arises from pluripotent stem cells $[1,2,7]$.

NSJ incidence in the newborn is approximately $0.3 \%$, equal between male and female patients. NSJ inheritance in an autosomal dominant type is quite frequent, as mosaicism results in HRAS, and KRAS genes [2,3,8-11]. These gene somatic mutations lead to an increase in nevus epithelial cells proliferation, which contributes to the benign and malignant skin appendages tumors appearance at the NSJ site $[2,3,5]$. Genes mosaicism is also associated with the appearance of a linear sebaceous nevus or SchimmelpenningFeuerstein-Mims syndrome (a neurocutaneous phakomatosis), which is characterized by a symptoms triad - a linear nevus, central nervous system, and vision organs disorders. Moreover, the extracutaneous clinical symptoms manifestations are observed at various times after birth $[2-4,8,10,12,13]$.

Most often, NSJ is found at birth, less often in infancy and early childhood. In every second case, the nevus is localized in the head area (scalp, forehead, face, the skin around the auricles, temporal region) and on the genitals. Clinically, at birth or somewhat later, NSJ is represented by a single, flat, or slightly elevated plaque of yellow, pinkish-yellow, yellowish-orange, or brown color. Multiple efflorescences are found very rarely. The nevus surface can be totally smooth, or partially hairless, less often and over time velvety-silky, velveteen-like, and/or papillomatous. 
Rash elements have a different shape: round, oval, linear, irregular, or polygonal. The linear configuration of the nevus sebaceous is noted in the Schimmelpenning-FeuersteinMims syndrome, while the elements are much larger and can be located along the Blaschko lines. The nevus size varies widely - from several millimeters up to $10 \mathrm{~cm}$, giant nevi are extremely rare $[2,3,6]$. In the puberty the nevus becomes thicker, as a result of the sebaceous glands and other skin appendages hyperplasia, its surface acquires a verrucous character and intense color.

In adulthood and old age, in $1 / 3$ cases in the NSJ area a variety of benign and malignant tumors appear, which are not limited to sebaceous differentiation. The papillary syringocystadenoma, tricholemoma, tricholemal cyst, and apocrine adenoma are more often diagnosed and formed on the scalp. Also, combinations of NSJ and verrucous epidermal nevus in one element could be diagnosed $[2,4,5]$. Basal cell carcinoma is most often registered among malignant tumors, developing in the NSJ area $[2,5,14,15]$. Sebaceous glands carcinoma, trichoblastoma, squamous cell carcinoma, apocrine carcinoma, eccrine porocarcinoma, melanoma, develop less frequently [2].

The NSJ pathomorphology depends on the stage and correlates with the patient's age. At an early stage, minor acanthosis, epidermis hyperpigmentation, sebaceous glands, and hair follicles hypoplasia with the eccrine glands ducts and apocrine glands disorganization are noted. During puberty, acanthosis in combination with papillomatosis, sebaceous gland hyperplasia, apocrine gland ectopia and cysts, and eccrine gland hyperplasia are observed. In adulthood and old age, papillomatous epidermal hyperplasia, sebaceous hyperplasia, and apocrine glands ectopia, hair follicle hypoplasia are observed [2-4,6].

Patients with NSJ may develop malignant or benign tumors; also, NSJ causes patients aesthetic and psychological discomfort. There are multiple treatment options, including curettage, cauterization, cryotherapy, photodynamic therapy, laser ablation, and surgical excision [6]. The surgical treatment timing is controversial. Some different recommendations for NSJ removal before puberty [16], or after puberty [6] were reported.

Visual NSJ diagnosis is not difficult, taking into account clinical signs, stage, and age features. In doubtful cases, non-invasive diagnostic methods and pathomorphological studies are used.

NSJ dermoscopic pattern features are changing with NSJ development stages $[17,18]$. The yellowish or brown globules aggregated in clusters on a yellow background related to the first stage of an alopecic patch, whitish-yellow lobular aspect, and grayish papillary appearance to verrucous plaques, a homogeneous yellow-whitish pattern related to nodules [17].

Dermoscopy is suggested as a useful method for the NSJ dynamical monitoring [17,18].

HFUS is used for the skin and skin appendages microstructure visualization and objective measurements. The pathomorphological changes localization, size, structure, and the borders with surrounding intact tissues could be examined with HFUS. It was reported that HFUS skin lesions measurements have a high correlation with histomorphometry [19-23].

Pathomorphological skin changes at HFUS scans are visually comparable with the histological images for the primary pathological processes in the epidermis, dermis, and subcutaneous fat [20]. HFUS is used for accurate depth and lateral borders detection for skin malignant and benign tumors [19-23]. Some specific HFUS patterns were described for BCC $[20,23]$.

At the present time HFUS skin examination could be provided at different frequencies in the $20-100 \mathrm{MHz}$ range. Frequencies of 20-33 MHz are used for all skin layers scanning, including epidermis, dermis, fat tissue, superficial fascias and muscles. $50-100 \mathrm{MHz}$ frequencies range are used for the targeted high resolution epidermis and dermis morphology visualization and measurements [22,23].

The non-invasive skin diagnostic methods combination was reported for the skin neoplasms differential diagnosis, as it allows the simultaneous study of dermoscopic patterns on the surface and micromorphological changes in the skin depth $[21,22]$.

In the available literature, we have found few publications about the NSJ ultrasound examination, and most reports were about extracutaneous pathology sonography [24-26] in patients with NSJ or about prenatal NSJ detection [27-28].

The present case report objective is to provide the NSJ high-resolution HFUS examination and describe the NSJ sonographic signs and features at 33 and $50 \mathrm{MHz}$.

\section{Clinical case}

Patient O., 12 y.o., male, living in Yakutsk (Russia) was admitted at the ANTA-Med clinic (Moscow, Russia) for diagnosis clarification.

\section{Anamnesis}

Nevus has existed since birth. In infancy and early childhood, flat shape grouped flesh-yellow and light yellow elements, were visualized. Patient's parents informed about plaque slow-growing and its slight color intensification over the past two years. Subjectively - without features. Heredity for phacomatosis and skin diseases is not burdened. The ultrasound examination of the kidneys, liver and hart, and brain MRI did not reveal pathological changes. The general and biochemical blood tests results are within normal limits. There was no vision and neurologic pathology in the anamnesis. The boy has a very good performance at school.

\section{Status localis}

The skin lesion limited and non-inflammatory. The elongated polygonal plaque of yellow and yelloworange color with discrete hemispherical yellowish papules on the periphery, located in the right preauricular and 
temporal-zygomatic area. The lesion surface is uneven, finely tuberous; individual papules significantly rise above the surrounding skin. On palpation - soft-elastic, mobile, painless formations (Figure 1).

For non-invasive examination the DUB SkinScanner (tpm-taberna pro medicum, Germany) skin imaging system was used. System was equipped with Videodermoscope (magnification x50 in polarized and non-polarized light) and high-frequency ultrasound probes 33 and $50 \mathrm{MHz} .33$ $\mathrm{MHz}$ probe (axial resolution $48 \mu$, scanning depth 8-10 $\mathrm{mm}$ ) was used for the scanning of the lesion and underlying tissues. $50 \mathrm{MHz}$ probe (axial resolution $31 \mu$, scanning depth 4-5 $\mathrm{mm}$ ) was used for the detailed epidermis and dermis morphology visualization and measurements [15,22].

\section{Videodermoscopy 50x with cross-polarization}

Multiple yellowish-white globules of a round and oval shape aggregated in clusters, and fine linear irregular or arborescent vessels visualized on the plaque surface (Figure $2 \mathrm{~b}$ ). The entire plaque surface was covered with thin fluffy hair (Figure $2 \mathrm{a}, \mathrm{b}$ ). Multiple follicles openings were blocked with the sebum secretion (Figure $3 \mathrm{a}, \mathrm{b}$ ). There was no dyschromia and dyspigmentation signs in the lesion periphery.

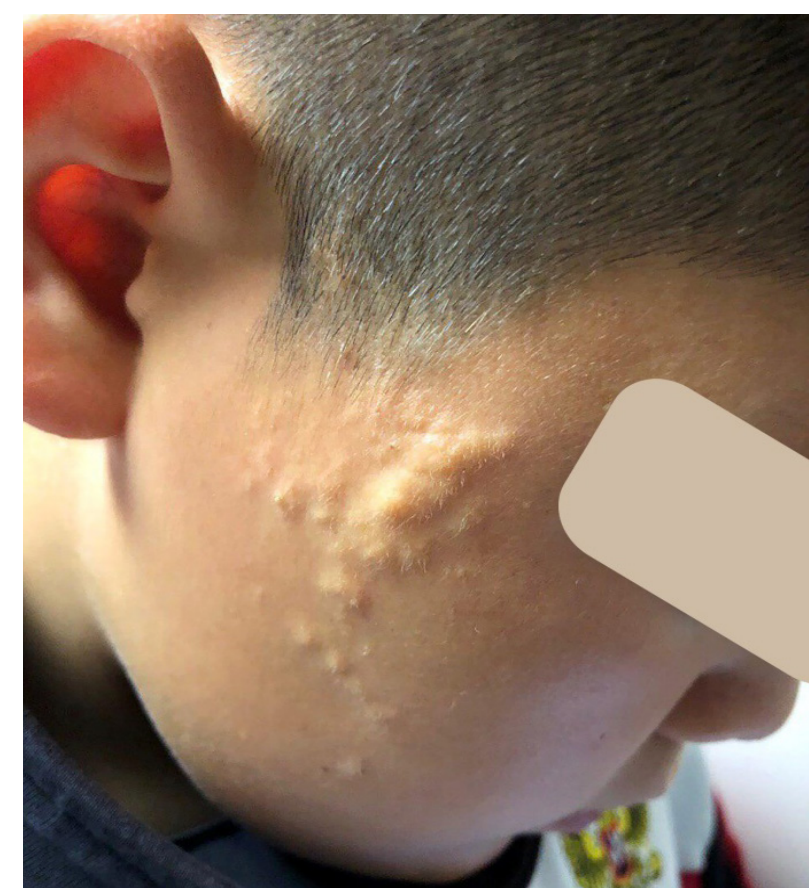

Figure 1. Patient's clinical photo.
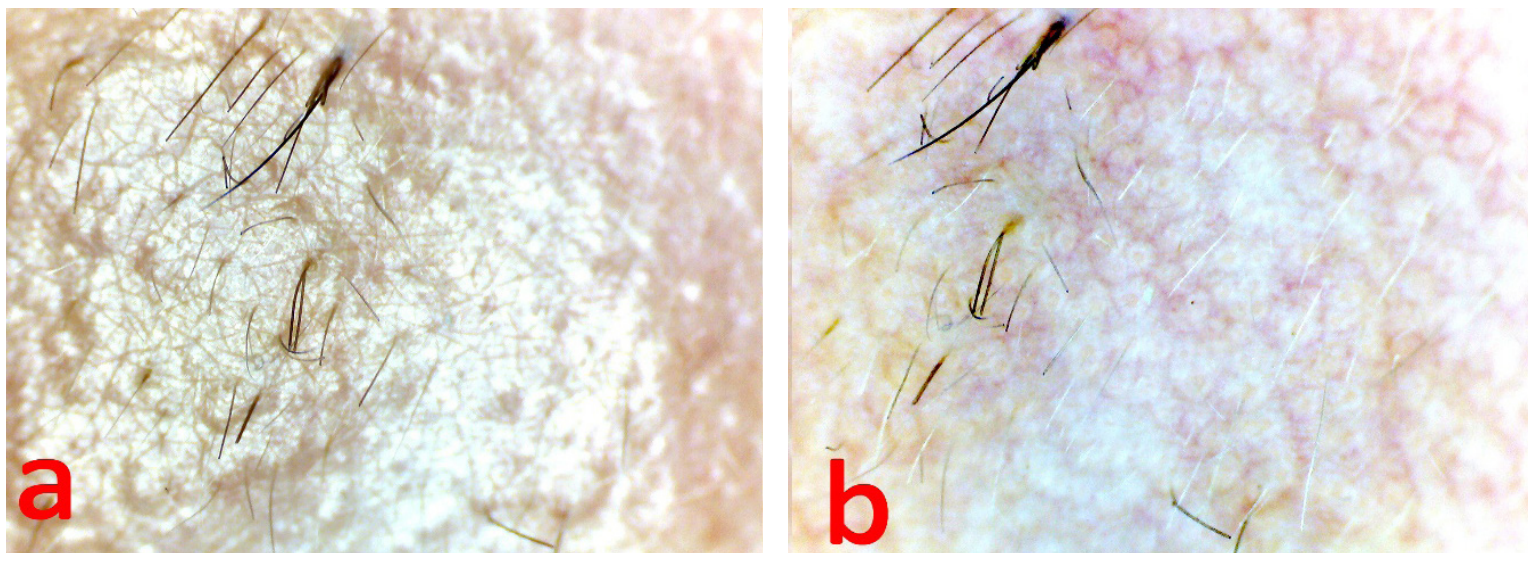

Figure 2. Videodermoscopy of the nevus plaque, a - in non-polarized light, b - in polarized light.
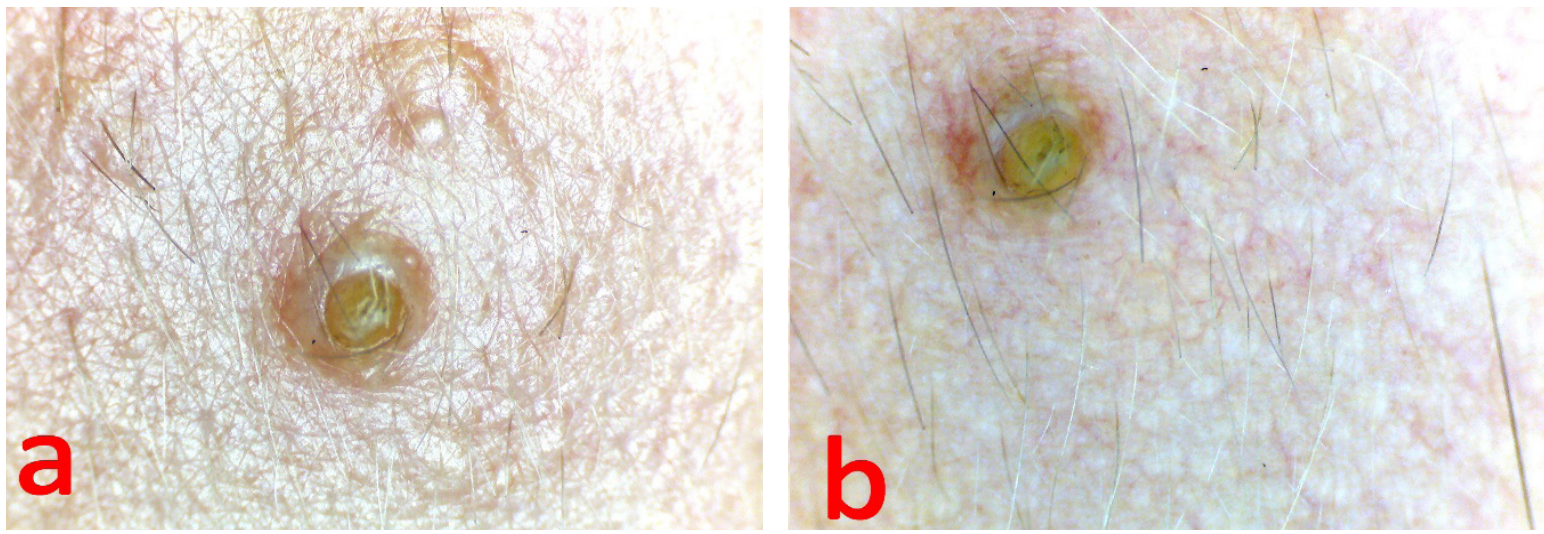

Figure 3. Videodermoscopy of follicle opening, blocked with the sebum secretion, a - in non-polarized light, b - in polarized light. 


\section{HFUS}

The lesions scanned with 33 and $50 \mathrm{MHz}$ probes, axial resolution 48 and 31 microns, scanning depth 8 and $5 \mathrm{~mm}$. Lesion scans (Figures $4 \mathrm{a}$ and $5 \mathrm{a}$ ) were compared with the intact skin control scans from the contralateral anatomical area (Figures $4 \mathrm{~b}$ and $5 \mathrm{~b}$ ).

The epidermis thickness in ROI was increased and irregular 137-238 $\mu$ (98-110 $\mu$ in the control area) (Figure $5 \mathrm{a}, \mathrm{b}$ ). Dermis thickness increased about three times up to 3-3.2 $\mathrm{mm}$ in comparison with the control area (1.1-1.25 mm) (Figures 4, 5). Multiple round- and ovalshaped hypo-anechoic areas visualized in the dermis. Hypo-anechoic areas, located perifollicular, had clear borders with the surrounding dermis and had sizes 08.-1.4 x 1.9-2.8 mm (Figure 5a). Multiple grouped and merged hypo-anechoic areas, located in the upper, medium, and deep dermis, had irregular borders and sized 0.16-0.36 x 0.4-0.8 mm (Figure 5a). Hypo-anechoic areas in the lower dermis were surrounded by hyperechoic dermal elements (Figure 5a). Lower dermal border with subcutaneous fat was deformed, but clear (Figures 4a, 5a), there were no changes in the fat tissue (Figures 4, 5).

The biopsy was not provided because patients parents did not agree and restrained form surgical treatment.

\section{Clinical diagnosis}

Linear Nevus sebaceus of Jadassohn.

\section{Recommendations}

Observe patient in dynamics every 6 months, until the decision about treatment option will be taken.
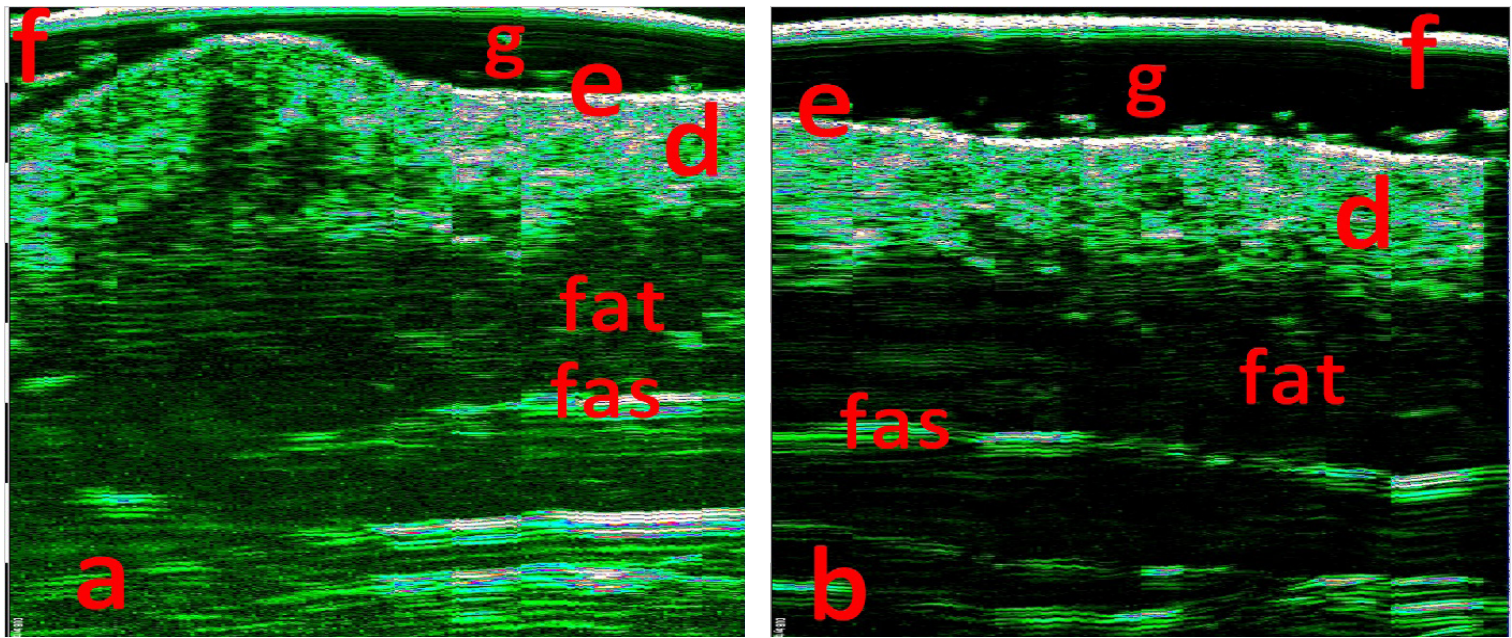

Figure 4. $33 \mathrm{MHz}$ scan at ROI (a) and $33 \mathrm{MHz}$ scan of the intact skin, (b) in the contralateral area. $\mathbf{f}$ - foil on the probe tip, $\mathbf{g}$ - contact gel, e - epidermis, $\mathbf{d}$ - dermis, fat - fat tissue, fas - superficial fascia.
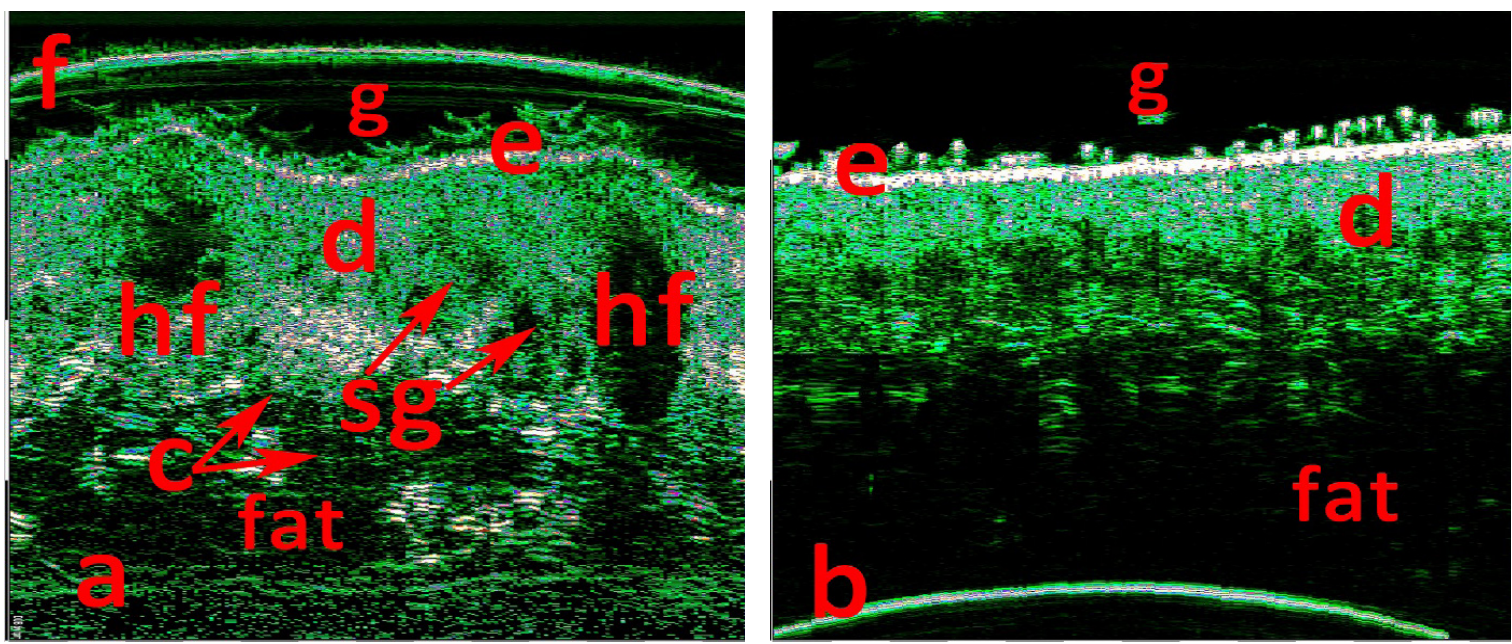

Figure 5. $50 \mathrm{MHz}$ scan at ROI (a) and $50 \mathrm{MHz}$ scan of the intact skin, (b) in the contralateral area. $\mathbf{f}$ - foil on the probe tip, $\mathbf{g}$ - contact gel, e - epidermis, d - dermis, fat - fat tissue, hf - hair follicle, sg - sebum gland conglomerate, $\mathbf{c}$ - cystic dilated glands ducts. 


\section{Discussion}

We have found some HFUS characteristics for NSJ. Epidermis thickness increase and irregularity detected on HFUS $50 \mathrm{MHz}$ scans may coincide with the acanthosis in the epidermis and papillomatosis. The hypo-anechoic oval perifollicular areas may correspond to follicular sebum gland hyperplasia ("hf" mark in figure 5a). The multiple grouped and merged hypo-anechoic areas, located in the upper and middle dermis, apparently matches with the sebum gland conglomerate ("sg" mark in figure 5a). Hypo-anechoic areas in the lower dermis, surrounded with hyperechoic dermal elements, most likely correspond to cystic dilated glands ducts ("c" mark in figure 5a).

In this clinical case, the videodermoscopic signs are similar to those described for the NSJ at puberty $[17,18]$.

NSJ management is controversial. Historically the excision in infancy was the treatment of choice because of basal cell carcinoma developing risk in the NSJ $[6,29,30]$. Nowadays, some publications indicate NSJ malignancy potential as $<1 \%$, and not likely in childhood [29-31]. The recent review contains different recommendations from dermatologists and plastic surgeons. In the UK, over $90 \%$ of plastic surgeons recommend excision in childhood, while $2 / 3$ of dermatologists consider waiting until adulthood [30].

Despite the treatment choice, NSJ management should include full-thickness tumor removal with clear margins $[6,32]$.

In the present case, we did not discover any extracutaneous pathology. The skin lesions had no malignancy signs. The nevus tissues were located in the dermis, without penetration in the fat tissue. The lower and lateral margins with surrounding tissues were clear. Taking in to account biopsy and histological examination impossibility, we have recommended dynamical observation, dermoscopic, and HFUS monitoring at least once in six months, or immediately if any signs of growing, texture, and color changes would be seen by patient's parents.

The HFUS NSJ signs and features described in this case report, combined with dermoscopy or videodermoscopy, could be helpful for noninvasive NSJ statement monitoring.

\section{References}

1. Kubanov A, Sysoeva T, Kovaleva J, Bisharova A, Mertsalova I. Skin appendages tumors. Brooke-Spiegler syndrome. Russian medical journal. Medical review. 2019;12:42-45.

2. Elkin V, Mitrukovskyi L, Sedova T. Particular dermatooncology. Part 1. Tumors, tumor-like formations and malformations of the epidermis and skin appendages. Perm, Perm publishing house LLC. 2017; pp. 744.

3. Olshanskaya A, Dujakova A, Schnider N, Dmitrienko D, Gezei T. Schimmelpenning-Feuerstein-Mims syndrome (clinical case report). Russian journal of pediatric neurology.
2017; 12:50-55.

4. Minaicheva L, Nazarenko L, Puzyreva O, Rare hereditary syndromes in the doctor practice: a group of epidermal nevus syndromes. Practical pediatric questions. 2012;7:70-72.

5. Karacheva J, Guzei T, Yakovleva T, Smykova A, Vinnik J. Basic cell cancer on the nevus sebaceus background: clinical picture and differential diagnosis. Vestnik dermatologii i venerologii. 2016;5: 51-54.

6. Gaydina T, Dvornikov A, Skripkina P, Arutyunyan G. Rationale for removing nevus sebaceus of Jadassohn in young patients. Bulletin of RSMU. 2018;3:80-83.

7. Molochkov VA, Mardi Sh. K razvitiju bazaliomy na fone nevusa sal'nyh zheljoz Jadassona. Al'manah klinicheskoj mediciny. 2007;15:232*235.

8. Aslam A, Salam A, Griffiths CE, McGrath JA. Naevus sebaceus: a mosaic RASopathy. Clin Exp Dermatol. 2014;39:1-6.

9. West C, Narahari S, Kwatra S, Feldman S. Autosomal dominant transmission of nevus sebaceous of Jadassohn. Dermatol Online J. 2012;18:17.

10. Groesser L, Herschberger E, Ruetten A, Ruivenkamp C, Lopriore E, Zutt M, et al. Postzygotic HRAS and KRAS mutations cause nevus sebaceous and Schimmelpenning syndrome. Nat Genet. 2012;44:783-787.

11. Levinsohn JL, Tian LC, Boyden LM, McNiff JM, Narayan $\mathrm{D}$, Loring ES, et al. Whole-exome sequencing reveals somatic mutations in HRAS and KRAS, which cause nevus sebaceus. J Invest Dermatol. 2013;133:827-830.

12. Avhad G, Ghuge P, Jerajani H. Cerebriform nevus sebaceous of Jadassohn. Indian Pediatr. 2013;50:1072.

13. Mahajan R, Dogra S, Kanwar AJ, Saikia UN, Agrawal S. Extensive cerebriform nevus sebaceus: an unusual presentation. Dermatol Online J. 2012;18:9.

14. Malhotra P, Arora D, Singh A. Squamous cell carcinoma, syringocystadenoma papilliferum and apocrine adenoma arising in a nevus sebaceus of Jadassohn. Indian J Pathol Microbiol. 2011;54:225-226.

15. Takeda H, Ikenaga S, Kaneko T, Nakajima K, Harada K, Hanada K, et al. Proliferating trichilemmal tumor developing in nevus sebaceous. Eur J Dermatol. 2010;20:664-665.

16. Al Hammadi A, Lebwohl MG. Nevus sebaceus. 2014. Medscape, updated 2018 Available at: http://emedicine. medscape.com/article/1058733-overview. .

17. Kelati A, Baybay H, Gallouj S, Mernissi FZ. Dermoscopic Analysis of Nevus Sebaceus of Jadassohn: A Study of 13 Cases. Skin Appendage Disord. 2017;3:83-91.

18. Zhuchkov MV, Bolshakova EE, Sonin DB, Rodionova SA. Dermatoscopic diagnostics of nevus sebaceous of Jadassohn. Vestnik Dermatologii i Venerologii. 2018;94(3):39-44.

19. Crisan M, Crisan D, Sannino G, Lupsor M, Badea R, Amzica F. Ultrasonographic staging of cutaneous malignant tumors: an ultrasonographic depth index. Arch Dermatol Res. 2013;305: 305-313.

20. X. Wortsman, G.B.E. Jemec (eds.). Dermatologic Ultrasound with Clinical and Histologic Correlations. Springer Science, New York, 2013: pp. 613. doi 10.1007/978-1-4614-7184-4_9 
21. Pellacani G, Seidenari S. Preoperative Melanoma Thickness Determination by $20-\mathrm{MHz}$ Sonography and Digital Videomicroscopy in Combination. Arch Dermatol. 2003;139:293-298.

22. Guitera P, Li LX, Crotty K, Fitzgerald P, Mellenbergh R, Pellacani G, et al. Melanoma histological Breslow thickness predicted by $75-\mathrm{MHz}$ ultrasonography. $\mathrm{Br} \mathrm{J}$ Dermatol. 2008;159:364-369.

23. Khlebnikova A, Molochkov V, Selezneva E, Belova L, Bezugly A, Sedova T, et al. Basal cell carcinoma invasion depth determined with 30 and $75 \mathrm{MHz}$ high-frequency ultrasound and histopathology - a comparative study. Med Ultrason. 2020;22:31-36.

24. Lihua J, Feng G, Shanshan M, Jialu X, Kewen J. Somatic KRAS mutation in an infant with linear nevus sebaceous syndrome associated with lymphatic malformations: A case report and literature review. Medicine (Baltimore). 2017;96:e8016.

25. Wang SM, Hsieh YJ, Chang KM, Tsai HL, Chen CP. Schimmelpenning syndrome: a case report and literature review. Pediatr Neonatol. 2014;55:487-490.

26. Resende C, Araújo C, Vieira AP, Ventura F, Celeste
B. Schimmelpenning syndrome. Dermatol Online J. 2013;19:20026.

27. Reitter A, Stücker AU, Buxmann H, Herrmann E, Haberl AE, Schlößer R, et al. Prenatal ultrasound screening for fetal anomalies and outcomes in high-risk pregnancies due to maternal HIV infection: a retrospective study. Infect Dis Obstet Gynecol. 2013;2013:208482.

28. Neis AE, Johansen KL, Harms RW, Watson WJ, Brost BC. Sonographic characteristics of linear nevus sebaceous sequence. Ultrasound Obstet Gynecol. 2006;27:323-324.

29. Fogelson SK, Dohil MA. Papular and Nodular Skin Lesions in Children. Semin Plast Surg. 2006;20:180-191.

30. Wali GN, Felton SJ, McPherson T. Management of naevus sebaceous: a national survey of UK dermatologists and plastic surgeons. Clin Exp Dermatol. 2018;43:589-591.

31. Idriss $\mathrm{MH}$, Elston DM. Secondary neoplasms associated with nevus sebaceus of Jadassohn: a study of 707 cases. J Am Acad Dermatol. 2014;70:332-337.

32. Van TN, Thanh HL, Manh TN, Thi Minh PP, Cao KP, Hong SN, et al. Efficacy of Surgical Excision for Nevus Sebaceous - Vietnamese Experience. Open Access Maced J Med Sci. 2019;7:211-213. 